OPEN ACCESS

Edited by:

Peer Briken,

University Medical Center Hamburg-Eppendorf, Germany

Reviewed by:

Dora Bianchi,

Sapienza University of Rome, Italy Claudio Longobardi, University of Turin, Italy

${ }^{*}$ Correspondence: Ricardo Barroso rbarroso@utad.pt

Specialty section:

This article was submitted to Health Psychology,

a section of the journal

Frontiers in Psychology

Received: 25 September 2020

Accepted: 27 January 2021

Published: 24 February 2021

Citation:

Barroso R, Ramião E,

Figueiredo P and Araújo AM (2021)

Abusive Sexting in Adolescence:

Prevalence and Characteristics

of Abusers and Victims.

Front. Psychol. 12:610474

doi: 10.3389/fpsyg.2021.610474

\section{Abusive Sexting in Adolescence: Prevalence and Characteristics of Abusers and Victims}

\author{
Ricardo Barroso ${ }^{1,2 *}$, Eduarda Ramião², Patrícia Figueiredo² and Alexandra M. Araújo ${ }^{3}$ \\ ' Department of Education and Psychology, University of Trás-os-Montes and Alto Douro, Vila Real, Portugal, ${ }^{2}$ Faculty \\ of Psychology and Education Sciences, University of Porto, Porto, Portugal, ${ }^{3}$ Department of Psychology and Education, \\ Portucalense University, Porto, Portugal
}

Sexting has been defined as sending, receiving, or forwarding sexually explicit messages, images, or photos to others through digital platforms, and can assume more consensual or more abusive and violent forms. This study aims to explore the prevalence of abusive sexting in Portuguese adolescents and the psychological characteristics of sexting abusers in terms of emotional and behavioral problems, potential markers of psychopathy, childhood trauma and maltreatment, and different forms of aggression. A cross-sectional study was conducted with 4,281 participants, aged 12-20 years (2,264 girls and 2,017 boys), of whom 204 (4.8\%) engaged in abusive sexting behaviors and $182(4.3 \%)$ self-identified as being a non-consensual sexting victim. Abusive sexting was more common among boys and middle adolescents, and abusive sexting victims were more likely to be children of single-parent families. Engaging in abusive sexting and being a victim of abusive sexting were also related to behavioral and emotional problems, callousness, experiences of neglect and abuse in childhood, and various forms of aggression. Implications for future research and intervention are discussed.

Keywords: sexting behavior, violence, adolescence, sexual behavior-psychology, sexuality, cyber abuse

\section{INTRODUCTION}

Nowadays, adolescents use personal technological devices for all types of social interactions, including sexual exploration and behavior. An adolescent practice of receiving public attention is the self-production of sexual images. Sexting can be described as sending or publishing sexually provocative text messages and images, including nude or half-nude photographs or videos, via mobile phones or the Internet (Mitchell et al., 2012; Cooper et al., 2016; Alonso and Romero, 2019). Sexting can also include receiving sexual texts and images of others, or exploiting image content or sexting behavior of others, by forwarding or sharing images (Drouin et al., 2013; Klettke et al., 2014; Cooper et al., 2016).

This practice can be seen as a normal and contemporary form of sexual expression and intimate communication within romantic and sexual relationships (Cooper et al., 2016; Englander, 2019; Barroso et al., 2020c), but also as a way of self-expression, exploration, and establishment of identity (Dir et al., 2013). In addition, images can be taken between friends, for example, as a joke (Cooper et al., 2016), or to increase popularity and acceptance within the peer group (Abeele et al., 2014). Some studies have observed that sexting is not always associated with other types of sexual harassment (Ross et al., 2019). While some studies report similar rates of self-producing 
and sending sexual images between genders (Dake et al., 2012; Rice et al., 2012), others have found different prevalence rates for girls and boys, with either boys being more likely to engage in sexually revealing self-exposures (Jonsson et al., 2014), or girls engaging more in sexting behaviors (Mitchell et al., 2012; Reyns et al., 2013; Martinez-Prather and Vandiver, 2014; Gregg et al., 2018).

If, on the one hand, sexting can be seen as a normative, consensual component of the exploration of sexuality during adolescence, on the other hand it may constitute a behavior of aggression and violence associated with various problems, such as risky sexual behavior or an increased likelihood of online victimization (Gámez-Guadix et al., 2017; Gámez-Guadix and de Santisteban, 2018; Marengo et al., 2019; Longobardi et al., 2020). The way the text message is performed and the use of sexual images can determine the legality of the adolescent's behavior. Sexual abuse may occur based on the dissemination of photos or videos of a person without their consent, and/or by forcefully exposing a person to sexual material, by, for example, forcing someone to watch movies or videos of people having sex (Barroso et al., 2020a,b). From a conceptual point of view, what technically defines the presence or absence of sexual violence, as well as the nature of the interaction and relationship in question, is consent, equality, and coercion (see Rich, 2003; Barroso, 2016). Therefore, consensual sexting (voluntarily sending sexual content) has been distinguished from non-consensual or abusive sexting (when an image is incorrectly used and sent without permission), being the latter a form of sexual violence (Walker et al., 2011; Alonso and Romero, 2019).

Given the heterogeneous nature of sexting, it is important to understand the different motivations that may underpin different sexting behaviors (Strohmaier et al., 2014; Bianchi et al., 2016). Sexting motivations related to sexual and social goals are more often listed, and experimental sexting sources are commonly considered (Drouin and Tobin, 2014; Walrave et al., 2015; Bianchi et al., 2016, 2017). Lee et al. (2016) suggest the most common reason to participate in sexting is related to peer pressure and coercion, specifically among girls. Higher social competence has been described as negatively related to engaging in all sexting behaviors, but particularly more for receiving and forwarding than for sending and receiving, and especially more for girls than for boys (Casas et al., 2019). Additionally, negative outcomes of sexting are much more common among certain groups, namely young teenagers or pre-teenagers, and those who experience negative pressure or coercion to sext, especially outside an established relationship (Rice et al., 2014). Recently, a study from Van Ouytsel et al. (2019) showed that sexual minority adolescents are more likely to experience, but not to perpetrate, abusive sexting behaviors. In line with this, the Cooper et al. (2016) review about sexting in adolescents identified four principal motivations for sexting, namely, (a) flirting and trying to get the romantic attention of a potential partner (Dir et al., 2013; Temple and Choi, 2014), (b) expressing normal sexuality within a dating relationship (Renfrow and Rollo, 2014), (c) experimenting with sexuality and identity (Chalfen, 2009; O'Sullivan, 2014), and (d) responding to pressure from one's partner or friends to conform to perceived normal behavior in the peer group (Walrave et al., 2014).

Identifying the factors that facilitate sexting among adolescents will help to achieve a better understanding of sexting in general, and of abusive sexting in particular, and also why adolescents engage in such risky behaviors. Among the studied correlates of sexting (Abeele et al., 2014; Hudson and Marshall, 2017), research has identified the influence of engaging in other sexual behaviors (Smith et al., 2014), the will to sext (van Oosten et al., 2017), a perceived need to seek popularity (Abeele et al., 2014), participating in cybergossip (Ringrose et al., 2013), and social competence (Bauman, 2015). Certain personality traits also seem to increase the likelihood of engaging in sexting: although most studies in this field were conducted with university students (see Whiteside and Lynam, 2001; Saulsman and Page, 2004; Ferguson, 2011; Settles et al., 2012; Delevi and Weisskirch, 2013; Dir et al., 2013), studies with adolescents showed relations between sexting and higher levels of sensation seeking (Van Ouytsel et al., 2014), as well as impulsivity (Temple et al., 2014). Similarly, a longitudinal study (Alonso and Romero, 2019) with adolescents from 12 to 19 years showed that adolescents who practice sexting are more likely to score higher on depression, impulsivity, and vulnerability. Thus, it is possible that adolescents who are more emotionally vulnerable may use sexting as a way to gain acceptance from their peers. In addition, the inability to control impulses can contribute to sending messages, photos and videos, without considering the possible consequences.

Internet addiction problems have been related to perceived maternal availability, cognitive reappraisal, and callousness traits (Trumello et al., 2018). In addition, some authors have shown interest in the study of factors associated with sexting in several dimensions such as family communication (Bianchi et al., 2019) and personality traits (e.g., honesty-humility, conscientiousness, emotionality, and extraversion; Morelli et al., 2020). However, there are few studies about factors that influence abusive sexting, namely if these factors may be associated with childhood traumas, psychopathic traits, or emotional problems.

The current study is innovative in this field, as it explores specifically abusive sexting, both in the perspective of the abuser and the victim, respectively, when the adolescent sends sexual pictures of another person, without their consent, or experiences cybervictimization because sexually explicit pictures or videos of themself were shared online with other people without consent. Accordingly, the purpose of the current study was to examine the prevalence and demographics of abusive sexting behaviors and abusive sexting victimization in a wide sample of Portuguese adolescents, and to explore the associations between abusive sexting and a set of psychological adjustment variables related to antisocial behavior and/or aggressive behavior perpetration (Moffitt, 1993; Loeber et al., 2008; Farrington, 2009). Sexting abusers are compared to adolescents who have not participated in such behaviors, and victims are compared with peers who have not had such an experience, in terms of emotional and behavioral problems, potential markers of psychopathy, childhood trauma and maltreatment, and different forms of aggression. The examination of links between abusive sexting and 
personal characteristics may provide crucial information for the identification of at-risk youth and the provision of timely and targeted prevention interventions.

\section{METHOD}

\section{Participants}

Data were drawn from the Interpersonal Violence Prevention Program (PREVINT) ${ }^{1}$ (Barroso et al., 2018). PREVINT is an original psychological intervention program designed to prevent the development and expression of aggression in adolescence. Previously to the intervention process, the project collected data from of 4,281 youth (ages 12-20; $M_{\text {age }}=14.51, S D=1.83$; 2,017 boys and 2,264 girls) attending 52 public middle- and high-schools, in rural and urban areas, from various districts of the country, both mainland and islands. Roughly half of the participants came from working-class families (51\%). According to the developmental stages of adolescence and young adulthood (Steinberg and Morris, 2001; Johnson et al., 2009), participants were classified as: early adolescents (12-13 years, $n=1,449$, $33.8 \%$ ), middle adolescents ( $14-16$ years, $n=2060,48.1 \%)$, and late adolescents (17-20 years, $n=772,18.0 \%)$. Regarding their socioeconomic status, they were classified as being from workingclass families $(n=1,217,28.4 \%)$ or middle- or upper-class families ( $n=3064,71.6 \%$ ). Most were children of married (or the legal equivalent) couples ( $n=3,097,72.3 \%)$, while the others were children of divorced (or the legal equivalent) or widowed singleparent households $(n=1,184,27.7 \%)$.

\section{MEASURES}

\section{Social Desirability Scale}

Social desirability scale (EDS-20; Almiro et al., 2016) is a selfreport measure, with 20 items of dichotomous response (yes/no), validated for the age groups in this sample. Example items include "Have you ever detested someone?" and "Have you ever taken advantage of someone?" Prior to data analyses, all participants were screened for social desirability, ruling out adolescents who scored over $M=14.73$, as they showed a tendency to transmit socially desirable responses rather than choosing responses that are a true reflection of their behaviors or feelings (Grimm, 2010). Cronbach's alpha for total scale was. 80 .

\section{Abusive Sexting}

Adolescents were asked two questions regarding sexting behaviors: (a) abusive sexting: "Have you ever shared sexually explicit images or videos of other people without their consent?"; and (b) abusive sexting victimization: "Have sexually explicit images or videos of yourself ever been shared with other people without your consent?." Answers were rated as $0=$ No, $1=$ Yes.

\section{Youth Self Report}

Youth self report (YSR; Achenbach and Rescorla, 2001; Portuguese version: Gonçalves et al., 2007). The YSR is a

${ }^{1}$ https://www.prevint.pt/en self-report questionnaire designed for school-age children and adolescents (ages 11-18) to obtain self-ratings of emotional, behavioral, and social problems. Items are rated on a threepoint scale $(0=$ not true, $1=$ somewhat or sometimes true, and 2 = very true or often true), based on the preceding 6 months. In this study, the syndromes Anxious/Depression (13 items; e.g., "I feel worthless or inferior"; $\alpha=0.85$ ), Social Problems (11 items; e.g., "I don't get along with other kids"; $\alpha=0.78$ ), Opposition (Rule Breaking) Behavior (16 items; e.g., " $I$ cut classes or skip school"; $\alpha=0.60)$, and Aggressive Behavior (17 items; e.g., "I destroy things belonging to others"; $\alpha=0.84$ ) were used. According to the criteria suggested by Ponterotto and Ruckdeschel (2007) regarding the adequacy of internal consistency measures, and considering the marginal alpha value of Opposition Behavior subscale $(\alpha=0.60)$ and the number of items (16 items), we decided to remove this scale from statistical analysis.

\section{Inventory of Callous-Unemotional Traits}

Inventory of callous-unemotional traits [ICU; Essau et al., 2006; Portuguese version by Pechorro et al. (2014)]. The ICU is a questionnaire designed to assess callous and unemotional traits on a 4-point scale ranging from 0 ("Not at all true") to 3 ("Definitely true"). This measure has been used with clinical and community samples of youth ranging from early adolescence to late adolescence/emerging adulthood (age range $=12-20$ years). Three subscales were used: Uncaring (eight items; e.g., "I hide my feelings from others"; $\alpha=0.86$ ), Callousness (11 items; e.g., "I do not care who I hurt to get what I want"; $\alpha=0.72)$, and Unemotional (five items; "I feel bad or guilty when I do something wrong"; $\alpha=0.43$ ). Although a low value of alpha could be due to a low number of questions (Nunnally, 1978), we decided to remove this scale from comparative statistical analysis.

\section{Childhood Trauma Questionnaire}

Childhood trauma questionnaire [CTQ; Bernstein et al., 2003; Portuguese version by Dias et al. (2013)]. The CTQ is a 28-item questionnaire aimed to quantify self-reported childhood trauma history in adolescent and adult populations (from 12 years old). Responses are measured on a 5-point Likert scale form 1 ("Never true") to 5 ("Very often true"). Childhood trauma was measured using five subscales: Emotional abuse (e.g., "I thought that my parents wished I had never been born"; $\alpha=0.81$ ), Emotional neglect (e.g., "I felt loved"; $\alpha=0.82$ ), Sexual abuse (e.g., "I believe that I was sexually abused"; $\alpha=0.89$ ), Physical abuse (e.g., "I believe that I was physically abused"; $\alpha=0.83$ ), and Physical neglect (e.g., "I don't have enough to eat"; $\alpha=0.60$ ). Each subscale contains five items, and an additional three items are intended to measure any tendency to minimize or deny the abuse.

\section{Reactive-Proactive Aggression Questionnaire}

Reactive-proactive aggression questionnaire (RPQ; Raine et al., 2006; Portuguese version by Pechorro et al., 2017). The RPQ is a 23 -item self-report measure that distinguishes between reactive 
and proactive aggression, with items scored on a frequency scale ranging from never $($ Score $=0)$ to often $($ Score $=2)$. Reactive aggression is characterized by high emotional activation, impulsivity, and hostility (e.g., "Reacted angrily when provoked by others"), and proactive aggression is characterized by a tendency toward instrumental, planned, non-empathetic, and cold strategy behavior (e.g., "Had fights with others to show who was on top"). Cronbach's alphas are.92 for the proactive subscale and.83 for the reactive subscale. This instrument has been used with samples of youth (ages 6-18 years), and adults (ages above 18 years).

\section{Buss-Perry Aggression Questionnaire-Short Form}

Buss-Perry aggression questionnaire-short form [BPAQ-SF; Buss and Perry, 1992; Bryant and Smith, 2001; Portuguese version by Pechorro et al. (2016)]. The BPAQ measures four aspects of human aggression, with 12 items scored on a 5-point scale (from 1 = "Extremely uncharacteristic of me" to $5=$ "Extremely characteristic of me"). The scales are: Physical Aggressiveness (three items; e.g., "There are people who pushed me so far that we came to blows"; $\alpha=0.77$ ), Verbal Aggressiveness (three items; e.g., "My friends say that I'm somewhat argumentative"; $\alpha=0.75$ ), Anger (three items; e.g., "I have trouble controlling my temper"; $\alpha=0.74$ ), and Hostility (three items; e.g., "Other people always seem to get the breaks"; $\alpha=0.79$ ). This instrument has been used with participants with ages of 11 years old and above.

\section{Procedures}

The participants were students from Portuguese schools. In addition to the institutional authorization from the Portuguese Ministry of Education, all participants were informed of the goals of the study and the confidentiality and anonymity of their responses were guaranteed. The research protocol was approved by University of Trás-osMontes and Alto Douro Ethics Committee. Written consent was collected from participants' parents/legal guardians. Data were collected through computer-assisted self-reports on school computers (or smartphones, when authorized) during regular classes by using an Internet-based survey hosted on a secure institutional server. Participation in this research was voluntary and did not imply any monetary payment or delivery of material goods.

\section{Data Analyses}

Frequencies, proportions, and chi-square tests were calculated to evaluate associations between engaging in abusive sexting and abusive sexting victimization, as well as differences by sex, age, and family background. Standardized residuals were analyzed to identify significant deviations of observed counts from expected frequencies. Student $t$-tests were calculated to analyze differences between sexting abusers and non-abusers and abusive sexting victims and non-victims. Cohen's $d$ statistics were calculated to determine effect sizes: with values of $0.20,0.50$, and
0.80 representing small, medium, and large effects, respectively (Cohen, 1988).

\section{RESULTS}

\section{Prevalence and Sociodemographic Factors}

From a total of 4,281 participants who completed the questionnaires, 204 (4.8\%) reported abusive sexting behaviors, i.e., sending unauthorized sexually explicit images or videos of others, and $182(4.3 \%)$ self-identified as being an abusive sexting victim, i.e., sexually explicit images or videos of themselves were shared without their consent. There was a significant association between engaging in abusive sexting and being an abusive sexting victim, $\chi^{2}(1)=132.15, p<0.001$. Adolescents both engaged in and victims of abusive sexting were more frequent than expected $(n=41)$. In addition, there were less cases than expected in being a sexting abuser but not a victim ( $n=163)$, as well as in being a victim, but not an abuser $(n=141)$.

Table 1 presents the associations between sociodemographic variables and abusive sexting behaviors, as well as abusive sexting victimization. A significant difference between the observed and expected frequency of abusive sexting behaviors was found in boys and girls: a higher number of sexting abusers was found for male adolescents $(n=143)$ than for female adolescents $(n=61)$. Although the number of abusive sexting victimization cases was higher for girls $(n=100)$ than for boys $(n=82)$, the association between gender and abusive sexting was not significant for victimization experiences.

There was also a significant association between age and engaging in abusive sexting: early adolescents (1213 years; $n=46$ ) were less likely and middle adolescents (14-16 years; $n=116$ ) were more likely to engage in abusive sexting behaviors. The inspection of standardized residuals indicated no significant difference between expected and counted frequencies of sexting abusers in late adolescents $(n=42)$. The number of abusive sexting victims was higher in middle adolescents $(n=97)$ than in early adolescents $(n=52)$ and late adolescents $(n=33)$. However, the association between age and abusive sexting victimization was not statistically significant.

No significant associations were found between family socioeconomic status and engaging in abusive sexting, nor abusive sexting victimization. Finally, no significant association was found between the parents' marital status and being a sexting abuser, but the association was observed for being an abusive sexting victim. Children of single-parent families were more likely than expected $(n=67)$ to be a victim of sexting than children of married couples.

\section{Group Differences for Psychological Adjustment Variables}

Systematic differences were found between adolescents who engaged in abusive sexting and those that did not, as 
shown in Table 2, for most of the studied psychological adjustment variables. When compared to those who did not engage in such behaviors, sexting abusers reported: significantly higher levels of aggressiveness, social problems, anxiety and depression; significantly more frequent experiences of emotional abuse, emotional neglect, sexual abuse, and physical neglect in childhood; significantly higher levels of callousness and lower levels of uncaring (but not unemotional) traits; significantly more frequent proactive and reactive aggression; and described themselves as significantly more physically and verbally aggressive, angry, and hostile. Such differences were also observed for the victims of abusive sexting, with the exception of uncaring traits, where no differences were found between groups. It is worthy to notice that the greatest differences between groups for abusive sexting was found in aggressiveness, proactive aggression, and physical aggression, and the least differences were found for traumatic experiences of emotional abuse in childhood, anxiety and depression, and anger. For abusive sexting victimization, differences were typically less expressive, compared to the ones observed for abusive sexting; nonetheless, the differences were higher in emotional abuse and sexual abuse, and lower in callous traits and anger.

\section{DISCUSSION}

The current study examined the prevalence and associations of engaging in abusive sexting and abusive sexting victimization and psychological adjustment variables in a sample of Portuguese adolescents. The prevalence of abusive sexting behaviors (4.8\%) and victimization $(4.3 \%)$ was lower than reported in prior studies (e.g., Gámez-Guadix et al., 2017; Gámez-Guadix and de Santisteban, 2018), which was expected as prior research focused on general and consensual forms of sexting. The prevalence in abusive sexting in boys and girls is not consistent with what has been known for general sexting (Casas et al., 2019), as in the current study boys were more likely than girls to engage in abusive sexting. These gender differences were also found in earlier studies, where sexting presented different patterns in girls and boys (Burén and Lunde, 2018; Casas et al., 2019). Family socioeconomic background was irrelevant for abusive sexting, but parental marital status was not, as the children from singleparent households were at a higher risk of being a victim of abusive sexting.

Abusive sexting was related to behavioral and emotional problems, which is consistent with prior research that identified mental health issues as correlates of sexting (Gámez-Guadix et al., 2017; Gámez-Guadix and de Santisteban, 2018). Prior studies suggested an association between sexting behaviors and personality characteristics, such as conscientiousness and extraversion (Temple and Choi, 2014; Gámez-Guadix and de Santisteban, 2018). Callous and unemotional traits were also related to abusive sexting. To our knowledge, this is the first study that has identified such a relation, suggesting that abusive sexting in adolescents may be related to personality-related variables, which are more stable and therefore of a worse prognosis for abusers. It is known that callous and unemotional traits are associated with aggression, bullying, and other antisocial behaviors (Ang and Goh, 2010). The association between sexting and such traits may be explained by a lack of empathy, not caring about others, and not feeling remorse.

In this study, abusive sexting was related to childhood experiences of physical, emotional, and sexual neglect and

TABLE 1 | Prevalence of abusive sexting behaviors and abusive sexting victimization.

\begin{tabular}{|c|c|c|c|c|c|c|}
\hline & \multicolumn{2}{|c|}{ Engaging in abusive sexting behaviors } & \multirow[b]{2}{*}{$\chi^{2}$} & \multicolumn{2}{|c|}{ Abusive sexting victimization } & \multirow[b]{2}{*}{$\chi^{2}$} \\
\hline & $\begin{array}{c}\text { No } \\
n(\%)\end{array}$ & $\begin{array}{c}\text { Yes } \\
n(\%)\end{array}$ & & $\begin{array}{c}\text { No } \\
n(\%)\end{array}$ & $\begin{array}{c}\text { Yes } \\
n(\%)\end{array}$ & \\
\hline \multicolumn{7}{|l|}{ Sex } \\
\hline Male & $1,874(92.9)$ & $143(7.1)$ & $45.41^{a \star \star \star}$ & 1,935 (95.9) & $82(4.1)$ & $0.32^{a}$ \\
\hline Female & 2, $203(97.3)$ & $61(2.7)$ & & $2,164(95.6)$ & $100(4.4)$ & \\
\hline \multicolumn{7}{|l|}{ Age } \\
\hline $\begin{array}{l}\text { Early adolescents } \\
\text { (12-13 years) }\end{array}$ & 1, $403(96.8)$ & $46(3.2)$ & $12.26^{b \star \star}$ & 1, $397(96.4)$ & $52(3.6)$ & $2.62^{b}$ \\
\hline $\begin{array}{l}\text { Middle adolescents } \\
\text { (14-16 years) }\end{array}$ & $1,944(94.4)$ & $116(2.7)$ & & 1, $963(95.3)$ & $97(4.7)$ & \\
\hline $\begin{array}{l}\text { Late adolescents } \\
\text { (17-20 years) }\end{array}$ & $730(94.6)$ & $42(5.4)$ & & $739(95.7)$ & $33(4.3)$ & \\
\hline \multicolumn{7}{|l|}{ Family socioeconomic status } \\
\hline Working-class & $1,156(95.0)$ & $61(5.0)$ & $0.23^{a}$ & $1,155(94.9)$ & $62(5.1)$ & $2.97^{a}$ \\
\hline Middle and upper-class & 2, $921(95.3)$ & $143(4.7)$ & & 2, $944(96.1)$ & $120(3.9)$ & \\
\hline \multicolumn{7}{|l|}{ Parents' marital status } \\
\hline Married or equivalent & 2, $951(95.3)$ & $146(4.7)$ & $0.01^{a}$ & 2, $983(96.3)$ & $114(3.7)$ & $8.78^{a \star \star}$ \\
\hline Single-parent, divorced or equivalent, or widowed & $1,113(95.2)$ & $56(4.8)$ & & 1, $102(94.3)$ & $67(5.7)$ & \\
\hline
\end{tabular}

${ }^{* *} p<0.01,{ }^{* * *} p<0.001 .{ }^{a} d f=1,{ }^{b} d f=2$. 
TABLE 2 | Group differences for psychological adjustment variables in abusive sexting behaviors and abusive sexting victimization.

\begin{tabular}{|c|c|c|c|c|c|c|c|c|}
\hline \multirow[b]{2}{*}{ Psychological adjustment variables } & \multicolumn{2}{|c|}{ Engaging in abusive sexting behaviors } & \multirow[b]{2}{*}{$t(3596)$} & \multirow[b]{2}{*}{$\begin{array}{c}\text { Cohen's } \\
d\end{array}$} & \multicolumn{2}{|c|}{ Abusive sexting victimization } & \multirow[b]{2}{*}{$t(3596)$} & \multirow[b]{2}{*}{$\begin{array}{c}\text { Cohen's } \\
d\end{array}$} \\
\hline & $\begin{array}{c}\text { No } \\
M(S D)\end{array}$ & $\begin{array}{c}\text { Yes } \\
M \text { (SD) }\end{array}$ & & & $\begin{array}{c}\text { No } \\
M(S D)\end{array}$ & $\begin{array}{c}\text { Yes } \\
M(S D)\end{array}$ & & \\
\hline Aggressiveness (YSR) & $9.10(5.31)$ & $12.23(7.42)$ & $-7.51^{\star \star \star}$ & 0.49 & $9.13(5.35)$ & $11.91(7.23)$ & $-6.27^{\star \star \star}$ & 0.44 \\
\hline Social problems (YSR) & $4.64(3.71)$ & $6.37(4.95)$ & $-5.96^{\star \star \star}$ & 0.40 & $4.64(3.72)$ & $6.49(4.86)$ & $-6.02^{\star \star \star}$ & 0.43 \\
\hline Anxiety and Depression (YSR) & $7.67(5.17)$ & $9.03(6.34)$ & $-3.38^{\star \star}$ & 0.24 & $7.63(5.17)$ & $10.01(6.20)$ & $-5.60^{\star \star \star}$ & 0.42 \\
\hline Emotional abuse (CTQ) & $8.18(3.83)$ & $9.04(4.48)$ & $-2.91^{\star \star}$ & 0.21 & $8.11(3.74)$ & $10.75(5.48)$ & $-8.46^{\star \star \star}$ & 0.56 \\
\hline Emotional neglect (CTQ) & $9.78(4.73)$ & $11.08(5.55)$ & $-3.56^{\star \star \star}$ & 0.25 & $9.78(4.75)$ & $11.20(5.25)$ & $-3.65^{\star \star \star}$ & 0.28 \\
\hline Sexual abuse (CTQ) & $5.85(2.55)$ & $6.82(3.92)$ & $-4.77^{\star \star \star}$ & 0.29 & $5.83(2.53)$ & $7.37(4.17)$ & $-7.18^{\star \star \star}$ & 0.44 \\
\hline Physical neglect (CTQ) & $6.81(2.76)$ & 8.25 (3.73) & $-6.65^{\star \star \star}$ & 0.44 & $6.83(2.79)$ & $7.93(3.45)$ & $-4.77^{\star \star \star}$ & 0.35 \\
\hline Callousness (ICU) & $11.56(5.28)$ & $14.13(5.63)$ & $-6.32^{\star \star \star}$ & 0.47 & $11.64(5.29)$ & $12.72(5.89)$ & $-2.49^{*}$ & 0.19 \\
\hline Uncaring (ICU) & $15.85(5.52)$ & $14.16(5.23)$ & $3.99^{\star \star *}$ & 0.32 & $15.80(5.52)$ & $15.00(5.59)$ & 1.77 & 0.14 \\
\hline Proactive aggression (RPQ) & $3.42(4.37)$ & $7.14(5.97)$ & $-10.86^{\star \star \star}$ & 0.71 & $3.52(4.45)$ & $5.54(5.82)$ & $-5.51^{\star \star \star}$ & 0.39 \\
\hline Reactive aggression (RPQ) & $7.25(4.12)$ & $9.44(5.05)$ & $-6.86^{\star \star \star}$ & 0.48 & $7.30(4.15)$ & $8.63(4.98)$ & $-3.90^{\star \star \star}$ & 0.29 \\
\hline Physical aggression (AQ) & $4.90(2.37)$ & $6.55(3.13)$ & $-8.90^{* * *}$ & 0.59 & $4.94(2.40)$ & $5.92(3.11)$ & $-4.92^{\star \star \star}$ & 0.35 \\
\hline Verbal aggression (AQ) & $6.08(2.60)$ & $7.17(3.23)$ & $-5.43^{\star \star *}$ & 0.37 & $6.10(2.60)$ & $6.91(3.05)$ & $-3.82^{\star \star \star}$ & 0.26 \\
\hline Anger (AQ) & $6.93(2.99)$ & $7.72(3.10)$ & $-3.42^{\star \star}$ & 0.26 & $6.94(2.98)$ & $7.77(3.40)$ & $-3.42^{\star \star}$ & 0.26 \\
\hline Hostility (AQ) & 7.25 (3.17) & $8.28(3.32)$ & $-.24^{\star \star \star}$ & 0.32 & $7.25(3.17)$ & 8.33 (3.32) & $-4.17^{\star \star \star}$ & 0.33 \\
\hline
\end{tabular}

${ }^{*} p<0.05,{ }^{* *} p<0.01$, and ${ }^{* * *} p<0.001$. 
abuse, suggesting that such past experiences may shape adolescents' proneness to disregard interpersonal respect and trust. Previous research suggests that adolescents who engage in abusive sexting behavior have histories marked with more frequent physical and sexual abuse experiences (Jonsson et al., 2014). Yoder et al. (2018) suggested that youth exposed to violence or adversity in their homes may engage in sexting because they are in an emotionally disinhibited state.

Finally, abusive sexting was related to various forms of aggression, including reactive and proactive aggression, and hostility, anger, and physical and verbal aggression. This finding validates the suggestion that abusive sexting can be considered as an expression of aggressive behavior, and that it will probably co-occur with other manifestations of aggression in adolescence. In other words, these results suggest that the psychological characteristics presented by these young abusers could be explained as another manifestation of general antisocial tendencies. Prior research has already shown an association between verbal aggression and physical aggression (Beckmann et al., 2017), and that physical aggression specifically in dating violence may be related to sexting (Dake et al., 2012). According to Englander (2012), adolescents in abusive sexting reported more often histories of dating violence in high-school, compared to both youth who sexted in the absence of coercion and those who did not sext at all.

Taken altogether, these findings suggest that sexting abusers are at a higher risk of emotional and behavioral problems. However, this is not only the case for abusers, but also for victims. The current study found that victims of abusive sexting also presented higher levels of intra- and interpersonal problems, also experienced more abuse and neglect in the past, and also engaged more frequently in aggressiveness, when compared to youth who did not have such an experience.

Albeit the contributions of this study, it is not without limitations. First, the cross-sectional design of this study limits inferences about causality. Future research could explore the temporal dynamics between abusive sexting and victimization and mental health issues, by employing longitudinal designs that follow participants from the transition from childhood to adolescence, and from adolescence into young adulthood. Second, this study relied solely on self-reported measures, which can lead to shared method variance and reporting bias. In the future, it would be valuable to include multi-informant data and observational or qualitative methods to strengthen our understanding of adolescents' experiences of abusive sexting and victimization. Third, the current study did not control for factors which may impact the results, such as dating and sexual experience. Future studies could further explore if abusive sexting occurs in the context of a dating relationship or if it is related to online deviant behavior, such as catfishing (i.e., pretending to be another person), inappropriate use of shared images, or even online theft or hacking personal presence online. Fourth,

\section{REFERENCES}

Abeele, M. V., Campbell, S. W., Eggermont, S., and Roe, K. (2014). Sexting, mobile porn use, and peer group dynamics: boys' and girls' self-perceived popularity, need for popularity, and perceived peer although participants were screened for social desirability, it is not guaranteed that all participants were all straightforward with their experiences of engaging in abusive sexting behaviors and especially in victimization. A cross-validation of the findings could be valuable with a new dataset, exploring the stability of prevalence and personal variables linked to abusive sexting across different samples. Finally, the current study did not explore other forms of sexting, including sending or receiving sexually explicit texts, and how and with whom do the adolescents exchange sexts with (e.g., a group of peers, adults, posting on social media platforms). Such details of abusive sexting could be explored in future studies.

Despite the limitations that may be identified, the current study contributes to research that attempts to describe and analyze abusive sexting in adolescence, by exploring the experiences of adolescents from a South-European country, and focusing on a particularly relevant type of sexting with close relations to cybervictimization. The findings suggest that abusive sexting, although not as widespread as more consensual forms of sexting, warrants further attention and research, as it is a damaging experience for adolescents' psychological adjustment, both for abusers and for victims. The present study has important implications for clinicians and counselors in an intervention process, particularly concerning childhood experiences of abuse and neglect, associated with abusive sexting behaviors and especially with victimization.

\section{DATA AVAILABILITY STATEMENT}

The raw data supporting the conclusions of this article will be made available by the authors, without undue reservation.

\section{ETHICS STATEMENT}

The studies involving human participants were reviewed and approved by Universidade de Trás-os-Montes and Alto Douro. Written informed consent to participate in this study was provided by the participants' legal guardian/next of kin.

\section{AUTHOR CONTRIBUTIONS}

All authors listed have made a substantial, direct and intellectual contribution to the work, and approved it for publication.

\section{FUNDING}

This work was funded by the Center for Psychology at the University of Porto, Foundation for Science and Technology Portugal (FCT UIDB/00050/2020).

pressure. Media Psychol. 17, 6-33. doi: 10.1080/15213269.2013.80 1725

Achenbach, T. M., and Rescorla, L. A. (2001). Manual for the ASEBA School-Age Forms \& Profiles. Burlington, VT: University of Vermont, Research Center for Children, Youth, \& Families. 
Almiro, P., Almeida, D., Ferraz, M., Ferreira, R., Perdiz, C., Dias, I., et al. (2016). "Escala de desejabilidade social de 20 itens (EDS-20) [20-item social desirability scale]," in Avaliação Psicológica em Contextos Forenses: Instrumentos Validados Para Portugal [Psychological Assessment in Forensic Contexts: Validated Instruments for Portugal], eds M. Simões, L. Almeida, and M. Gonçalves (Lisboa: Pactor/Lidel).

Alonso, C., and Romero, E. (2019). Conducta de sexting en adolescentes: predictores de personalidad y consecuencias psicosociales en un año de seguimiento. Anal. Psicol. 35, 214-224. doi: 10.6018/analesps.35.2.339831

Ang, R. P., and Goh, D. H. (2010). Cyberbullying among adolescents: the role of affective and cognitive empathy, and gender. Child Psychiatry Hum. Dev. 41, 387-397. doi: 10.1007/s10578-010-0176-3

Barroso, R. (2016). "Violência sexual," in Dicionário Crime, Justiça e Sociedade, eds R. L. Maia, L. M. Nunes, S. Caridade, A. I. Sani, R. Estrada, C. Nogueira, et al. (Lisboa: Edições Sílabo), 530-531. (Coords.).

Barroso, R., Figueiredo, P., and Ramião, E. (2018). "Intervenção no âmbito da violência nas relações de namoro: Resultados preliminares do projeto Violentómetro," in Violências no Namoro, eds S. Neves, and A. Correia (Porto: Edições ISMAI), 153-174.

Barroso, R., Figueiredo, P., Ramião, E., and Fanti, K. (2020a). Using psychopathy to identify differences between variants of juveniles who have committed sexual offenses. J. Sex. Aggress. doi: 10.1080/13552600.2019.1705407

Barroso, R., Pechorro, P., Figueiredo, P., Ramião, E., Manita, C., Gonçalves, R. A., et al. (2020b). Are juveniles who have committed sexual offenses the same everywhere? Psychometric properties of the Juvenile Sex Offender Assessment Protocol-II in a Portuguese youth sample. Sex. Abuse J. Res. Treatment 32, 606-825. doi: 10.1177/1079063219858070

Barroso, R., Ribeiro, M., Ramião, E., and Figueiredo, P. (2020c). “Dating violence perpetration by male and female adolescents," in Adolescent Dating Violence: Outcomes, Challenges and Digital Tools, ed. S. Caridade (Toronto: Nova Science Publishers), 35-48.

Bauman, S. (2015). "Cyberbullying and sexting: school mental health concerns," in Mental Health Practice in Today's Schools: Issues and Interventions, eds R. H. Witte and G. S. Mosley-Howard (New York, NY: Springer), 450-460.

Beckmann, L., Bergmann, M. C., Fischer, F., and Mößle, T. (2017). Risk and protective factors of child-to-parent violence: a comparison between physical and verbal aggression. J. Interpers. Viol. 1-26. doi: 10.1177/0886260517746129

Bernstein, D. P., Stein, J. A., Newcomb, M. D., Walker, E., Pogge, D., Ahluvalia, T., et al. (2003). Development and validation of a brief screening version of the childhood trauma questionnaire. Child Abuse Negl. 27, 169-190. doi: 10.1016/ s0145-2134(02)00541-0

Bianchi, D., Morelli, M., Baiocco, R., and Chirumbolo, A. (2016). Psychometric properties of the sexting motivations questionnaire for adolescents and young adults. Rassegna Psicol. 3, 5-18.

Bianchi, D., Morelli, M., Baiocco, R., and Chirumbolo, A. (2017). Sexting as the mirror on the wall: body-esteem attribution, media models, and objectifiedbody consciousness. J. Adolesc. 61, 164-172. doi: 10.1016/j.adolescence.2017. 10.006

Bianchi, D., Morelli, M., Baiocco, R., and Chirumbolo, A. (2019). Individual differences and developmental trends in sexting motivations. Curr. Psychol. 1-10. doi: 10.1007/s12144-019-00398-4

Bryant, F., and Smith, B. (2001). Refining the architecture of aggression: a measurement model for the Buss-Perry aggression questionnaire. J. Res. Pers. 35, 138-167. doi: 10.1006/jrpe.2000.2302

Burén, J., and Lunde, C. (2018). Sexting among adolescents: a nuanced and gendered online challenge for young people. Comput. Hum. Behav. 85, 210-217. doi: 10.1016/j.chb.2018.02.003

Buss, A. H., and Perry, M. (1992). The aggression questionnaire. J. Pers. Soc. Psychol. 63, 452-459. doi: 10.1037/0022-3514.63.3.452

Casas, J. A., Ojeda, M., Elipe, P., and Del Rey, R. (2019). Exploring which factors contribute to teens' participation in sexting. Comput. Hum. Behav. 100, 60-69. doi: $10.1016 /$ j.chb.2019.06.010

Chalfen, R. (2009). 'It's only a picture': sexting, 'smutty' snapshots and felony charges. Vis. Stud. 24, 258-268. doi: 10.1080/14725860903309203

Cohen, J. (1988). Statistical Power Analysis for the Behavioral Sciences, 2nd Edn. Mahwah, NJ: Lawrence Earlbaum Associates.

Cooper, K., Quayle, E., Jonsson, L., and Svedin, C. G. (2016). Adolescents and self-taken sexual images: a review of the literature. Comput. Hum. Behav. 55, 706-716. doi: 10.1016/j.chb.2015.10.003
Dake, J. A., Price, J. H., Maziarz, L., and Ward, B. (2012). Prevalence and correlates of sexting behavior in adolescents. Am. J. Sex. Educ. 7, 1-15. doi: 10.1080/ 15546128.2012.650959

Delevi, R., and Weisskirch, R. S. (2013). Personality factors as predictors of sexting. Comput. Hum. Behav. 29, 2589-2594. doi: 10.1016/j.chb.2013.06.003

Dias, A., Sales, L., Carvalho, A., Castro-Vale, I., Kleber, R., and Cardoso, R. M. (2013). Estudo de propriedades psicométricas do questionário de trauma de infância - Versão breve numa amostra portuguesa não clínica. Lab. Psicol. 11, 103-120. doi: 10.14417/lp.11.2.713

Dir, A. L., Coskunpinar, A., Steiner, J. L., and Cyders, M. A. (2013). Understanding differences in sexting behaviors across gender, relationship status, and sexual identity, and the role of expectancies in sexting. Cyberpsychol. Behav. Soc. Network. 16, 568-574. doi: 10.1089/cyber.2012.0545

Drouin, M., and Tobin, E. (2014). Unwanted but consensual sexting among young adults: relations with attachment and sexual motivations. Comput. Human Behav. 31, 412-418. doi: 10.1016/j.chb.2013.11.001

Drouin, M., Vogel, K. N., Surbey, A., and Stills, J. R. (2013). Let's talk about sexting, baby: computer-mediated sexual behaviors among young adults. Comput. Hum. Behav. 29, A25-A30. doi: 10.1016/j.chb.2012.12.030

Englander, E. (2012). Low Risk Associated with Most Teenage Sexting: A Study of 617 18-Year-Olds. Bridgewater State University, MA: Massachusetts Aggression Reduction Center.

Englander, E. (2019). What do we know about sexting, and when did we know it? J. Adolesc. Health 65, 577-578. doi: 10.1016/j.jadohealth.2019.08.004

Essau, C. A., Sasagawa, S., and Frick, P. J. (2006). Callous-unemotional traits in a community sample of adolescents. Assessment 13, 454-469. doi: 10.1177/ 1073191106287354

Farrington, D. P. (2009). "Conduct disorder, aggression and delinquency," in Handbook of Adolescent Psychology: Individual Bases of Adolescent Development, Vol. 1, eds R. M. Lerner and L. Steinberg (Hoboken, NJ: Wiley), $683-722$.

Ferguson, C. J. (2011). Sexting behaviors among young Hispanic women: incidence and association with other high-risk sexual behaviors. Psychiatric Q. 82, 239243. doi: 10.1007/s11126-010-9165-8

Gámez-Guadix, M., and de Santisteban, P. (2018). "Sex pics?”: longitudinal predictors of sexting among adolescents. J. Adolesc. Health 63, 608-614. doi: 10.1016/j.jadohealth.2018.05.032

Gámez-Guadix, M., Santisteban, P., and Resett, S. (2017). Sexting among Spanish adolescents: prevalence and personality profiles. Psicothema 29, 29-34. doi: 10.7334/psicothema2016.222

Gonçalves, M., Dias, P., and Machado, B. C. (2007). Questionário de Autoavaliação Para Jovens YSR 11-18 (T.M. Achenbach, 2001). Porto: Universidade do Minho e Universidade Católica Portuguesa.

Gregg, D., Somers, C. L., Pernice, F. M., Hillman, S. B., and Kernsmith, P. (2018). Sexting rates and predictors from an Urban Midwest high school. J. School Health 88, 423-433. doi: 10.1111/josh.12628

Grimm, P. (2010). “Social desirability bias," in Wiley International Encyclopedia of Marketing, eds J. N. Sheth and N. K. Malhotra (Hoboken, NJ: John Wiley \& Sons Ltd.).

Hudson, H. K., and Marshall, S. A. (2017). Consequences and predictors of sexting among selected southern undergraduates. Int. J. Sex. Health 30, 20-27. doi: 10.1080/19317611.2017.1404540

Johnson, S. B., Blum, R. W., and Giedd, J. N. (2009). Adolescent maturity and the brain: the promise and pitfalls of neuroscience research in adolescent health policy. J. Adolesc. Health 45, 216-221. doi: 10.1016/j.jadohealth.2009.05.016

Jonsson, L. S., Priebe, G., Bladh, M., and Svedin, C. G. (2014). Voluntary sexual exposure online among Swedish youth - social background, internet behavior and psychosocial health. Comput. Hum. Behav. 30, 181-190. doi: 10.1016/j.chb. 2013.08.005

Klettke, B., Hallford, D. J., and Mellor, D. J. (2014). Sexting prevalence and correlates: a systematic literature review. Clin. Psychol. Rev. 34, 44-53. doi: 10.1016/j.cpr.2013.10.007

Lee, C.-H., Moak, S., Walker, J. T., Lee, C.-H., Moak, S., and Walker, J. T. (2016). Effects of self-control, social control, and social learning on sexting behavior among south Korean youths. Youth Society 48, 242-264. doi: 10.1177/ 0044118 X13490762

Loeber, R., Slot, W., and Stouthamer-Loeber, M. (2008). "A cumulative developmental model of risk and promotive factors," in Tomorrow's Criminals: The Development of Child Delinquency and Effective Interventions, eds R. 
Loeber, N. W. Slot, P. H. van der Laan, and M. Hoeve (Farnham: Ashgate), 133-164.

Longobardi, C., Fabris, M. A., Prino, L. E., and Settanni, M. (2020). The role of body image concerns in online sexual victimization among female adolescents: the mediating effect of risky online behaviors. J. Child Adolesc. Trauma doi: 10.1007/s40653-020-00301-5

Marengo, D., Settanni, M., and Longobardi, C. (2019). The associations between sex drive, sexual self-concept, sexual orientation, and exposure to online victimization in Italian adolescents: investigating the mediating role of verbal and visual sexting behaviors. Child. Youth Serv. Rev. 102, 18-26. doi: 10.1016/j. childyouth.2019.04.023

Martinez-Prather, K., and Vandiver, D. M. (2014). Sexting among teenagers in the United States: a retrospective analysis of identifying motivating factors, potential targets, and the role of a capable guardian. Int. J. Cyber Criminol. 8, 21-35.

Mitchell, K. J., Finkelhor, D., Jones, L. M., and Wolak, J. (2012). Prevalence and characteristics of youth sexting: a national study. Pediatrics 129, 13-20. doi: 10.1542/peds.2011-1730

Moffitt, T. E. (1993). Adolescence-limited and life-course-persistent antisocial behavior: a developmental taxonomy. Psychol. Rev. 100, 674-701. doi: 10.1037/ 0033-295X.100.4.674

Morelli, M., Chirumbolo, A., Bianchi, D., Baiocco, R., Cattelino, E., Laghi, F., et al. (2020). The role of HEXACO personality traits in different kinds of sexting: a cross-cultural study in 10 countries. Comput. Hum. Behav. 113:106502. doi: 10.1016/j.chb.2020.106502

Nunnally, J. C. (1978). Psychometric Theory, 2nd Edn. New York, NY: McGrawHill.

O'Sullivan, L. F. (2014). Linking online sexual activities to health outcomes among teens. New Dir. Child Adolesc. Dev. 144, 37-51.

Pechorro, P., Barroso, R., Poiares, C., Oliveira, J. P., and Torrealday, O. (2016). Validation of the Buss-Perry aggression questionnaire-short form among Portuguese juvenile delinquents. Int. J. Law Psychiatry 44, 75-80. doi: 10.1016/ j.ijlp.2015.08.033

Pechorro, P., Ray, J., Barroso, R., Marôco, J., and Gonçalves, R. (2014). Validation of the Inventory of callous-unemotional traits among a Portuguese sample of detained juvenile offenders. Int. J. Offend. Ther. Comparat. Criminol. 60, 349-365. doi: 10.1177/0306624X14551256

Pechorro, P., Ray, J. V., Raine, A., Maroco, J., and Goncalves, R. A. (2017). The reactive-proactive aggression questionnaire: validation among a Portuguese sample of incarcerated juvenile delinquents. J. Interpers. Viol. 32, 1995-2017. doi: $10.1177 / 0886260515590784$

Ponterotto, J. G., and Ruckdeschel, D. E. (2007). An overview of coefficient alpha and a reliability matrix for estimating adequacy of internal consistency coefficients with psychological research measures. Percept. Motor Skills 105, 997-1014. doi: 10.2466/pms.105.3.997-1014

Raine, A., Dodge, K., Loeber, R., Gatzke-Kopp, L., Lynam, D., Reynolds, C., et al. (2006). The reactive-proactive aggression questionnaire: differential correlates of reactive and proactive aggression in adolescent boys. Aggress. Behav. 32, 159-171. doi: 10.1002/ab.20115

Renfrow, D. G., and Rollo, E. A. (2014). Sexting on campus: minimizing perceived risks and neutralizing behaviors. Deviant Behav. 35, 903-920. doi: 10.1080/ 01639625.2014.897122

Reyns, B. W., Burek, M. W., Henson, B., and Fisher, B. S. (2013). The unintended consequences of digital technology: exploring the relationship between sexting and cybervictimization. J. Crime Justice 36, 1-17. doi: 10.1080/0735648x.2011. 641816

Rice, E., Gibbs, J., Winetrobe, H., Rhoades, H., Plant, A., Montoya, J., et al. (2014). Sexting and sexual behavior among middle school students. Pediatrics 134, e21-e28. doi: 10.1542/peds.2013-2991

Rice, E., Rhoades, H., Winetrobe, H., Sanchez, M., Montoya, J., Plant, A., et al. (2012). Sexually explicit cell phone messaging associated with sexual risk among adolescents. Pediatrics 130, 667-673. doi: 10.1542/peds.2012-0021

Rich, P. (2003). "The juvenile sexual offender: commonalities and characteristics," in Juvenile Sexual Offenders: Understanding, assEssing and Rehabilitating, ed. P. Rich (Hoboken, NJ: Wiley), 38-57.

Ringrose, J., Harvey, L., Gill, R., and Livingstone, S. (2013). Teen girls, sexual double standards and "sexting": gendered value in digital image exchange. Feminist Theory 14, 305-323. doi: 10.1177/146470011349 9853

Ross, J., Drouin, M., and Coupe, A. (2019). Sexting coercion as a component of intimate partner polyvictimization. J. Interpers. Viol. 34, 2269-2291. doi: $10.1177 / 0886260516660300$

Saulsman, L. M., and Page, A. C. (2004). The five-factor model and personality disorder empirical literature: a meta-analytic review. Clin. Psychol. Rev. 23, 1055-1085. doi: 10.1016/j.cpr.2002.09.001

Settles, R. E., Fischer, S., Cyders, M. A., Combs, J. L., Gunn, R. L., and Smith, G. T. (2012). Negative urgency: a personality predictor of externalizing behavior characterized by neuroticism, low conscientiousness, and disagreeableness. J. Abnorm. Psychol. 121, 160-172. doi: 10.1037/a0024948

Smith, P. K., Thompson, F., and Davidson, J. (2014). Cyber safety for adolescent girls. Curr. Opin. Obstetr. Gynecol. 26, 360-365. doi: 10.1097/gco. 0000000000000106

Steinberg, L., and Morris, A. S. (2001). Adolescent development. Annu. Rev. Psychol. 52, 83-110. doi: 10.1146/annurev.psych.52.1.83

Strohmaier, H., Murphy, M., and DeMatteo, D. (2014). Youth sexting: prevalence rates, driving motivations, and the deterrent effect of legal consequences. Sex. Res. Soc. Policy 11, 245-255. doi: 10.1007/s13178-014-0162-9

Temple, J., and Choi, H. (2014). Longitudinal association between teen sexting and sexual behavior. Pediatrics 134, e1287-e1292. doi: 10.1542/peds.2014-1974

Temple, J. R., Le, V. D., van den Berg, P., Ling, Y., Paul, J. A., and Temple, B. W. (2014). Brief report: teen sexting and psychosocial health. J. Adolesc. 37, 33-36. doi: 10.1016/j.adolescence.2013.10.008

Trumello, C., Babore, A., Candelori, C., Morelli, M., and Bianchi, D. (2018). Relationship with parents, emotion regulation, and callous-unemotional traits in adolescents' internet addiction. Biomed. Res. Int. 23:7914261. doi: 10.1155/ 2018/7914261

van Oosten, J. M. F., Peter, J., and Vandenbosch, L. (2017). Adolescents's sexual media use and willingness to engage in casual sex: differential relations and underlying processes. Hum. Commun. Res. 43, 127-147. doi: 10.1111/hcre. 12098

Van Ouytsel, J., Van Gool, E., Ponnet, K., and Walrave, M. (2014). Brief report: the association between adolescents' characteristics and engagement in sexting. J. Adolesc. 37, 1387-1391. doi: 10.1016/j.adolescence.2014. 10.004

Van Ouytsel, J., Walrave, M., and Ponnet, K. (2019). An exploratory study of sexting behaviors among heterosexual and sexual minority early adolescents. J. Adolesc. Health 65, 621-626. doi: 10.1016/j.jadohealth.2019.06.003

Walker, S., Sanci, L., and Temple-Smith, M. (2011). Sexting and young people: expert's views. Youth Stud. Austr. 30, 8-16.

Walrave, M., Heirman, W., and Hallam, L. (2014). Under pressure to sext? Applying the theory of planned behaviour to adolescent sexting. Behav. Informat. Technol. 33, 86-98. doi: 10.1080/0144929X.2013.837099

Walrave, M., Ponnet, K., Van Ouytsel, J., Van Gool, E., Heirman, W., and Verbeek, A. (2015). Whether or not to engage in sexting: explaining adolescent sexting behaviour by applying the prototype willingness model. Telematics Informatics 32, 796-808. doi: 10.1016/j.tele.2015.03.008

Whiteside, S. P., and Lynam, D. R. (2001). The five-factor model and impulsivity: using a structural model of personality to understand impulsivity. Pers. Individ. Diff. 30, 669-689. doi: 10.1016/s0191-8869(00)00064-7

Yoder, J., Hansen, J., and Precht, M. (2018). Correlates and outcomes associated with sexting among justice involved youth: the role of developmental adversity, emotional disinhibitions, relationship context, and dating violence. Child. Youth Serv. Rev. 94, 493-499. doi: 10.1016/j.childyouth.2018.08.020

Conflict of Interest: The authors declare that the research was conducted in the absence of any commercial or financial relationships that could be construed as a potential conflict of interest.

Copyright (C) 2021 Barroso, Ramião, Figueiredo and Araújo. This is an open-access article distributed under the terms of the Creative Commons Attribution License (CC BY). The use, distribution or reproduction in other forums is permitted, provided the original author(s) and the copyright owner(s) are credited and that the original publication in this journal is cited, in accordance with accepted academic practice. No use, distribution or reproduction is permitted which does not comply with these terms. 